\title{
Reflexões sobre as Diretrizes Curriculares Nacionais para a formação de professores da educação básica
}

\author{
Marco Antônio Margarido Costa*
}

Resumo: Este trabalho é parte da pesquisa que resultou em nossa tese de doutoramento, na qual investigamos o funcionamento do discurso político-educacional e didático-pedagógico da formação de professores de Inglês, à luz da Analise de Discurso de orientação pecheutiana. Neste artigo, apresentamos alguns resultados da análise documental (discurso político-educacional) da pesquisa, que tomou como exemplares de discurso as Diretrizes Curriculares Nacionais para a Formação de Professores da Educação Básica, em nível superior, curso de licenciatura, de graduação plena e as Diretrizes Curriculares para os cursos de Letras. A análise questiona alguns aspectos que os referidos documentos abordam e explora alguns efeitos de sentido que determinados conceitos e orientações ali encontrados podem provocar na realidade escolar, sobretudo em educadores envolvidos com o processo de formação de professores.

Palavras-chave: Formação de professores, Diretrizes Curriculares, Análise de Discurso.

Abstract: This work is part of the research carried out for our doctoral thesis, in which we investigated the configuration of the political, educational and pedagogical discourse of the English teacher education based on Pêcheux's theoretical and philoso-

Doutor em Letras pela Universidade de São Paulo. Possui experiência na área de Ensino-Aprendizagem de Língua Inglesa, Linguística Aplicada, em especial Análise de Discurso e Formação de Professores de Inglês. Professor Adjunto da Universidade Federal de Campina Grande - PB. E-mail: marcanco@terra.com.br 
phical concepts of Discourse Analysis. In this article, we present some results of the analysis of a part of the research, namely the political/educational discourse in a corpus made up of the National Guidelines for Teacher Education Programs and the National Guidelines for Language and Literature Programs. The analysis questions some aspects mentioned in the documents and explore a few effects of meaning some concepts and guidelines can provoke in the schooling system, specially among educators involved with the teacher education process.

Keywords: Teacher education, Guidelines, Discourse Analysis.

\section{Introdução}

Com o objetivo de refletir sobre o interior dos cursos de formação de professores, analisamos documentos instituídos no âmbito do Conselho Nacional de Educação (CNE), a saber: Diretrizes Curriculares Nacionais para a Formação de Professores da Educação Básica, em nível superior, curso de licenciatura, de graduação plena e Diretrizes Curriculares Nacionais para os cursos de Letras. Os referidos documentos propóem um conjunto de orientações norteadoras para a formulação do projeto pedagógico dos referidos cursos.

Neste artigo, apresentamos os resultados da análise desses documentos a partir de uma perspectiva discursiva da linguagem que contempla aspectos sociais, históricos e ideológicos para a construção de sentidos. Dessa perspectiva, o texto não é apenas um conjunto de palavras que tem sentidos previamente determinados e únicos.

Por entendermos que as referidas Diretrizes Curriculares Nacionais preconizam formas de educar e de ver o indivíduo, ou seja, elas são resultados de uma construção social de sentidos, mobilizamos reflexôes de Bauman (2001) sobre a pós-modernidade. Esse sociólogo emprega a designação "modernidade líquida" para indicar a fluidez do estágio presente da atualidade, que se contrapóe 
a uma noção de modernidade "sólida", período marcado pela busca da totalidade, da perfeição e do domínio de saberes.

Salientamos que não vemos nesses documentos propostas definitivas para a elaboração curricular dos cursos de formação de professores, de modo geral, como também para os cursos de formação de professores de Letras. Tampouco é nosso interesse propor alteraçôes em seu texto. Buscaremos evidenciar que, considerando a complexidade de alguns princípios apresentados, somos da opinião de que toda reforma curricular deve ser amplamente discutida por todos que estão envolvidos no processo educacional. Sendo assim, nossa argumentação toma então as Diretrizes Curriculares como exemplares de discurso, apontando para fragmentos discursivos que, por se mostrarem ambivalentes, podem propiciar a continuidade de um determinado tipo de formação docente.

Como percebemos marcas de ambivalência nas Diretrizes Curriculares, isto é, as orientações apresentadas podem, naturalmente, ser desdobradas, desmembradas, ou apontar para rumos distintos, adotamos a "disjunção" como categoria de análise para abordarmos o corpus constituído por tais documentos. Vemos que a disjunção pode ser um modo de mostrar a ambivalência que, para nós, é noção presente em várias áreas do saber, em conceitos, nas relações humanas e para nosso propósito, nas discussões educacionais. Dessa forma, iniciamos a discussão, apontando para essas marcas de ambivalência, para esse desdobrar de sentidos no discurso desses documentos. O presente artigo está subdividido em seções que levam em consideração momentos de irrupção dessa ambivalência.

Conforme esclarecemos, as Diretrizes Curriculares para os cursos de Letras destinam-se a estabelecer normas para esses cursos de graduação, visando orientar a formulação do projeto pedagógico dos referidos cursos. Esse documento, que apresenta considerações acerca de suas características básicas e princípios norteadores, é formulado a partir dos seguintes tópicos: a) o perfil dos formandos nas modalidades bacharelado e licenciatura; b)as competências gerais e habilidades específicas a serem 
desenvolvidas durante o período de formação; c) os conteúdos caracterizadores básicos e os conteúdos caracterizadores de formação profissional, inclusive os conteúdos definidos para a educação básica, no caso das licenciaturas; d) a estruturação do curso; e, finalmente, e) as formas de avaliação.

Em alguns trechos desse documento, há também referências às orientações constantes nas Diretrizes Curriculares Nacionais para a Formação de Professores da Educação Básica (de ora em diante DCF), cujo teor busca contemplar a organização curricular de cada instituição, a concepção, o desenvolvimento e abrangência dos cursos de formação, a construção do projeto pedagógico e as competências profissionais, entre outros aspectos.

\section{Adequar-se para mudar ou mudar para adequar-se?}

Passemos à análise das Diretrizes, iniciando com itens propostos nas Diretrizes Curriculares para os cursos de Letras (de ora em diante DCL). Em seu parágrafo inicial, identificamos o que poderíamos chamar de objetivo principal dessas DCL:

Esta proposta de Diretrizes Curriculares leva em consideração os desafios da educação superior diante das intensas transformações que têm ocorrido na sociedade contemporânea, no mercado de trabalho e nas condições de exercício profissional. Concebe-se a Universidade não apenas como produtora e detentora do conhecimento e do saber, mas, também, como instância voltada para atender às necessidades educativas e tecnológicas da sociedade. Ressalta-se, no entanto, que a Universidade não pode ser vista apenas como instância reflexa da sociedade e do mundo do trabalho. Ela deve ser um espaço de cultura e de imaginação criativa, capaz de intervir na sociedade, transformando-a em termos éticos. (CONSELHO NACIONAL DE EDUCAÇÃO / CÂMARA DE EDUCAÇÃO SUPERIOR - CNE/CES, 2001, grifos nossos). 
O primeiro aspecto que ressaltamos é a preocupação com as "transformaçôes na sociedade contemporânea e no mercado de trabalho". Conforme analisamos em outro trabalho (COSTA, 2008), há aqui uma vinculação das reformas educacionais às mudanças ocorridas na sociedade, justificativa que parece seguir uma tendência mundial (LINDBLAD; POPKEWITZ, 2004). Logo em seguida, o esclarecimento sobre o papel da universidade de "atender às necessidades educativas e tecnológicas da sociedade”. Percebemos, nessas formulações, uma ênfase para que a universidade satisfaça à sociedade não apenas como instrumento de produção de conhecimento, mas que também volte seu olhar para as exigências do mercado de trabalho, sobretudo para as transformações tecnológicas ocorridas.

[...] é imperativo examinar as forças ideológicas e materiais que têm contribuído para o que desejo chamar de proletarização do trabalho docente, isto é, a tendência de reduzir os professores ao status de técnicos especializados dentro da burocracia escolar, cuja função, então, torna-se administrar e implementar programas curriculares, mais do que desenvolver ou apropriar-se criticamente de currículos que satisfaçam objetivos pedagógicos específicos (GIROUX, 1997, p. 158).

Kaufman apud Kincheloe (1997, p. 60) postula que existe uma política invisível da escolarização que objetiva produzir indivíduos adaptáveis às necessidades do mercado. Giroux (1997) também nos alerta que:

Por isso, um questionamento se impõe em relação ao sentido do termo "tecnologia". Para Popkewitz (1998), ele é usado para designar um plano de aula, por exemplo. Podemos ampliar essa reflexão, ao considerarmos estudo de Coracini (2007), no qual ela analisa as relações conflituosas no imaginário de professores sobre o fenômeno da globalização e novas tecnologias (vídeo, televisão, internet, multimídia etc.). A autora pesquisa o modo como o marketing das novas tecnologias gera conflitos e tensões na constituição das subjetividades dos professores. Para ela, o desenvolvimento tecnológico forma um imaginário que 
mitifica as novas tecnologias, transformando-as em recursos indispensáveis para o ensino. Daí surge o conflito dos professores; pois, desafiados diante desse "efeito de verdade" produzido, desejam dominar as novas tecnologias, mas, ao mesmo tempo, deparam-se com a falta de conhecimento diante do novo que fragiliza sua autoridade frente aos "saberes" veiculados por meio das novas tecnologias. Percebemos, então, como os deslizamentos de sentidos são passíveis de ocorrer, fato que reforça a importância de discussões não apenas sobre esses documentos, mas sobre qualquer outro destinado a "organizar" uma realidade escolar.

Supondo que esse termo (tecnologia) pode indicar qualquer técnica moderna e complexa, pensamos, por exemplo, no universo da informática. Entendemos que as novas tecnologias podem e devem ser incorporadas às práticas pedagógicas. Entretanto, acreditamos ser pertinente, primeiramente, pensarmos em formas de transformar os recursos oferecidos pelas novas tecnologias em maneiras de produzir conhecimento. Ou seja, o professor deve ser instigado a interferir criticamente nas informações coletadas via internet, por exemplo.

Concebe-se, comumente, o mundo "virtual" como fonte infinita de possibilidades com amplos instrumentos para auxiliar ou até mesmo "atrair" o aluno para a aula. Entendemos que é necessário ponderar sobre o uso desses recursos para não se correr o risco de transformá-los em "regimes de verdade", segundo Foucault (2003a). Ou seja, versões de "verdade" são elaboradas e estabelecidas que, envoltas por um caráter transcendente desses recursos tecnológicos, tornam-se mecanismos de controle e de opressão. Por um lado, aqueles indivíduos desprovidos de tais recursos tornam-se "excluídos" de uma rede mais ampla de comunicação. Por outro lado, os detentores dos mais sofisticados recursos podem assumir uma posição que favorece o controle, $\mathrm{O}$ saber e, consequentemente, o poder.

Por meio dessa discussão, não queremos sugerir que a menção à tecnologia, nos documentos, é inadequada ou inconsequente. Pelo contrário, o que advogamos é que há temas que demandam escrutínio constante. Desse modo, a questão é verificar se, e como, 
os debates acerca do tema "novas tecnologias" estão inseridos no momento da elaboração do currículo, das escolhas das disciplinas, enfim, na extremidade em que elas produzirão seus efeitos: a sala de aula. Lembramos estudo sobre o impacto das tecnologias da informação e da comunicação (TIC), em contextos educacionais, de Barreto (2005), argumentando que há uma "fetichização" de tais recursos, promovida pelo mercado, como se representassem "solução mágica" para problemas educacionais. A autora investiga resultados de pesquisas desenvolvidas em escolas na cidade do Rio de Janeiro sobre as TIC e aponta práticas que, revestidas de um caráter inovador (por exemplo, utilização do processador de texto Word), revelavam "prática velha e sem sentido" (ditado de palavras). A pesquisadora defende a necessidade de se inventar e socializar táticas que viabilizem o trabalho com as TIC com a intenção de "agregar novos sentidos à formação e ao trabalho docente" (BARRETO, 2005, p. 156).

De acordo com Kincheloe (1997, p. 173), ao incorporar modelos à sua prática, os professores "permitem que o poder molde suas vidas profissionais”. Na verdade, Foucault (2003b, 2003c) argumenta que o poder também produz saber, ele não é apenas um dispositivo que serve para censurar ou oprimir. Portanto, entendemos que "para atender às necessidades educativas e tecnológicas da sociedade”, os professores devem estar atentos para que isso não os torne dependentes ou seguidores de uma nova rede global de informaçôes, acreditando que as novas tecnologias garantem um "ensino melhor".

Peters (1994) nos diz que a noção de "cultura de empresa" pode ser a criação de uma metanarrativa ${ }^{1}$. Ele argumenta que:

Essa nova metanarrativa está baseada numa nova visão do futuro. A linguagem usada para sustentar essa visão é uma linguagem de 'excelência', 'inovação, melhoria e modernização', 'obter mais

1 O autor faz referência a Lyotard (1986) e suas reflexôes sobre a pós-modernidade. Para esse pensador francês, as metanarrativas ou metarrelatos são versões de histórias (pessoais, políticas, morais, religiosas etc.) que são transmitidas pelas culturas a fim de legitimá-las. 
com menos', 'alfabetização tecnológica', 'revolução na informação e nas telecomunicações', 'marketing e gerência internacionais', 'treinamento de habilidades', 'desempenho' e 'empresa' (PETERS, 1994, p. 222).

Isto posto, desejamos enfatizar, portanto, que vemos a possibilidade de preparar um futuro professor, utilizando avançados recursos tecnológicos para "satisfazer" o mercado de trabalho. Contudo, parece-nos indispensável pensar sobre a maneira como os recursos tecnológicos são utilizados no cotidiano escolar. É inevitável considerar aqui, novamente, reflexão de Foucault sobre as ramificações do poder no momento que se torna capilar (2003d). É na sua extremidade (espaço sala de aula) que a inserção de técnicas e instrumentos (computadores, referências ao mundo virtual, consultas a internet) pode possibilitar a criação de uma soberania do saber e, portanto, de dominação. Dependendo do modo como alunos, professores, instituiçôes escolares passem a utilizar-se de tais recursos tecnológicos, atribuindolhes característica de fonte inesgotável de saber e possibilidades, assumindo-os como discursos de verdade, esses recursos podem tornar-se mecanismos produtores de discriminação na escola e na sociedade como um todo.

Destacaremos, ao longo da análise, trechos que identificamos como, eminentemente, de efeito retórico no discurso, como vimos acima acerca do termo "tecnologia". Mas, voltemos à questão do papel da universidade.

O segundo ponto que destacamos trata da criação de um duplo que formulamos como produzir/sofrer reflexo da sociedade. Ou seja, há o investimento na universidade para ela ser capaz de intervir, transformar, enfim, ser ativa, mas, ao mesmo tempo, há a instauração de um par oposto que descreve a passividade, ou a aceitação da universidade como apenas um reflexo da sociedade. O que acenamos, nesse momento, é um desdobramento do que chamamos de bifurcação de sentidos ou criação de pares/duplos. A formulação de que a "Universidade não pode ser vista apenas como reflexo da sociedade e do mundo, mas sim como espaço 
de cultura, imaginação criativa, com capacidade de intervenção e transformação na sociedade [...]" coloca em cena uma característica da pós-modernidade: a (re)distribuição de deveres, segundo interpretação de Bauman (2001). Com a citada formulação, pode-se ler que a universidade deve ser capaz de..., ou seja, ela passa a ter essa atribuição. Há, desse modo, uma transferência de obrigaçôes, pois discursivamente não se nota se essa tarefa estava sob a responsabilidade de um outro que não a Universidade. Entendemos que essa transferência de obrigações pode ocorrer em diversos níveis, não apenas partindo do Estado para o indivíduo, pois da ótica da fluidez (BAUMAN, 2001), há um deslizamento constante inclusive sobre a desregulamentação de obrigações. O fato que nos interessa é observar como os deslizamentos de sentidos ocorrem e as implicações daí advindas. Apple (1994, p. 63), por exemplo, nos alerta que as diretrizes e metas curriculares objetivam responsabilizar as escolas "pelo sucesso ou fracasso de seus alunos". Desse modo, conforme defendemos anteriormente, nossa crítica aos documentos é no sentido de provocar reflexões acerca das possíveis representações discursivas, a fim de entender como elas funcionam e, principalmente, agir sobre elas.

Outro momento que identificamos como sendo, eminentemente, de efeito retórico no discurso diz respeito ao objetivo principal dessas DCL. Retomamos formulação mencionada no parágrafo anterior, chamando a atenção para um fragmento que parece ficar à margem das discussões: "ela [universidade] deve ser um espaço de cultura e de imaginação criativa, capaz de intervir na sociedade, transformando-a em termos éticos". Pensamos que tal atribuição de tarefa à universidade demanda, entre outros aspectos, tempo, debates e investigação sobre o conceito de ética, como ele é explorado nas instituições de ensino, quem está autorizado a discutir tal tema nas universidades. Concluímos que a forma como essa questão é proposta nos documentos pode fazer com que a noção de ética incorra em um espaço vazio que não cala, fato que, no nosso ponto de vista, imprime no discurso um efeito de distanciamento, de inoperância das propostas. 


\section{A "flexibilidade" como palavra de ordem}

Após refletirmos sobre os objetivos dessas Diretrizes, lançamos também um olhar para os princípios norteadores presentes nas DCL:

Os princípios que norteiam esta proposta de Diretrizes Curriculares são a flexibilidade na organização do curso de Letras e a consciência da diversidade / heterogeneidade do conhecimento do aluno, tanto no que se refere à sua formação anterior, quanto aos interesses e expectativas em relação ao curso a ao futuro exercício da profissão. A flexibilização curricular, para responder às novas demandas sociais a aos princípios expostos, é entendida como a possibilidade de:

- eliminar a rigidez estrutural do curso;

- imprimir ritmo e duração ao curso, nos limites adiante estabelecidos;

- utilizar, de modo mais eficiente, os recursos de formação já existentes nas instituições de ensino superior. (CNE/CES, 2001, grifos nossos).

Nesse excerto, observamos a materialização de palavras de ordem, como resultado da disseminação de conceitos que a realidade pós-moderna faz propagar. O estudo de Maguire (2004), por exemplo, analisa processos de "modernização" no contexto escolar inglês e suas implicações para os professores. Nos documentos analisados, sugere-se que o professor contemporâneo seja flexível. Compreendemos que, nas DCL, a flexibilidade é outorgada aos profissionais envolvidos com a questão curricular, que devem "imprimir ritmo", "utilizar recursos" e "eliminar rigidez", ou seja, ela está presente, é parte inerente, pois dito desse modo, ela é suposta como existente. É interessante notar como essa característica de flexibilidade apresenta simultaneamente seu duplo, sua outra face, criando um par que designaremos como flexibilidade/rigidez. Ou seja, não há como dissociar essas noções, pois essa flexibilidade irá, fatalmente, apresentar limites, ou ainda, a flexibilização poderá vir a ser negada ou rejeitada, o que levará ao aparecimento do seu duplo: a rigidez. Notemos ainda como a 
incisa "de modo mais eficiente" ajuda a criar esse efeito binário. Depreende-se, portanto, que os recursos de formação existentes nas instituições de ensino superior não são ou podem não ser utilizados de modo eficiente, que visem à flexibilização.

Os termos "diversidade" e "heterogeneidade", apontados no excerto anterior, parecem pertinentes para uma discussão que leve em consideração os preceitos de uma educação pós-moderna, quais sejam: a desestabilização das verdades únicas, o descentramento e reformulação de conceitos e perspectivas etc. (KIZILTAN; BAIN; CAÑIZARES, 1993; USHER; EDWARDS, 1994; KINCHELOE, 1997, et al). Antes, porém, para o propósito de nossa reflexão, acatamos contribuições dos estudos linguísticos de Authier-Revuz (2001, 2004), para quem, em todo discurso, há inscrições de marcas linguísticas de diversos enunciadores, isto é, dizeres formulados de diferentes pontos de vista. Segundo essa autora, a heterogeneidade é constitutiva do sujeito, do discurso e do dizer. Partindo de tal premissa, cabe questionarmos, em nossa análise, como o professor irá desenvolver práticas que deem conta dessa perspectiva. Para Silva (2003, p. 76), numa perspectiva dos estudos culturais, tanto "a identidade como a diferença têm que ser ativamente produzidas [...] Somos nós que as fabricamos, no contexto de relações culturais e sociais”. Nossa preocupação, portanto, reside no fato de que, se o docente que prepara futuros professores para o exercício do magistério não estiver alerta sobre a complexidade das questões que envolvem a diversidade (raça, classe socioeconômica, origem, variações linguísticas etc.) e a heterogeneidade (formações discursivas, perspectivas enunciativas, efeitos de sentido etc.), levando em conta uma perspectiva discursiva, seu trabalho didático-pedagógico poderá voltar-se apenas para maneiras pré-estabelecidas de buscar e manter homogeneidades em sua sala de aula.

Lembramos reflexões de McLaren (1997), prefaciando o trabalho de Giroux, que endossam nossas preocupações com o tema da diversidade: 
Como podem os problemas relacionados com classe, raça, gênero e poder serem traduzidos em questões de qualidade e excelência educacional? De que maneira podemos nos reposicionar enquanto educadores contra a cultura dominante a fim de reconstituir nossas próprias identidades e experiências e aquelas de nossos estudantes? Como é possível reconhecer a diferença e as múltiplas formas de identidade e ainda assim abordar as questões de vontade e luta política? Que diversidade silenciamos em nome de uma pedagogia libertadora? (MCLAREN, 1997, p. xiii).

Acreditamos que essa "consciência" (da diversidade/heterogeneidade) almejada pelas Diretrizes requer do docente um maior engajamento para desvendar, em sua prática, formas autoritárias e não críticas de ensinar, camufladas por uma atitude criativa e libertadora. Esse engajamento deve traduzir-se em pesquisa, em utilização de recursos semióticos, etnográficos, conforme aponta Kincheloe (1997). Esses são alguns caminhos, pois não há garantias de que isso possa despertar no educador uma percepção mais acurada das particularidades de cada aprendiz.

Faz-se necessário olharmos também para os princípios norteadores das DCF, nos quais há destaque para a formação docente, objetivando preparar para:

I. o ensino visando à aprendizagem do aluno;

II. o acolbimento e o trato da diversidade;

III. o exercício de atividades de enriquecimento cultural;

IV. o aprimoramento em práticas investigativas;

V. a elaboração e a execução de projetos de desenvolvimento dos conteúdos curriculares;

VI. o uso de tecnologias da informação e da comunicação e de metodologias, estratégias e materiais de apoio inovadores;

VII. o desenvolvimento de hábitos de colaboração e de trabalho em equipe. (CONSELHO NACIONAL DE EDUCAÇÃO / CONSELHO PLENO - CNE/CP, 2002, Art. $2^{\circ}$, grifos nossos). 
A forma como as noções mencionadas nesse fragmento (acolhimento, aprimoramento etc), está materializada linguisticamente (substantivos precedidos por artigos definidos), produz um efeito de que elas prescindem de maiores explicações, como se fossem unívocas. Assim, os enunciados ${ }^{2}$ desse fragmento colaboram com a criação de um discurso difuso, fato que reforça algumas postulações anteriores sobre a possibilidade de se manter o status quo por meio de leis que deixarão o professor refém de práticas já cristalizadas, ao não precisar posturas e condutas. Lembramos que essas formulações fundamentam não apenas as DCL, mas também as Diretrizes de diversos cursos (Filosofia, História, Geografia etc.). Dessa forma, caberia problematizar também como cada um desses cursos daria conta de aspectos como "o acolhimento e o trato da diversidade", "o uso de tecnologias da informação", entre outros, a partir de fragmentos tão "abertos" e genéricos.

O segundo aspecto que observamos nesse excerto é a presença de algumas palavras de ordem ou expressões que passaram a fazer parte de um discurso pós-moderno: "diversidade", "práticas investigativas", "tecnologias da informação", "materiais de apoio inovadores", "hábitos de colaboração e de trabalho em equipe". Entendemos que essas expressões no texto das DCF parecem contempladas ou "metamorfoseadas" nas DCL com o uso do termo "flexibilidade", se a tomarmos como significado de ligeireza de movimentos ou ainda "aptidão do espírito para se aplicar a diversas ocupações e estudos” (HOUAISS, 2001). Assim, o termo "flexibilidade" contempla todas as outras qualidades sugeridas (capacidade de aceitar diferenças, de ser investigativo, inovador, cooperativo etc.). Enfim, notamos que os conceitos podem "viajar” por várias partes do mundo, conforme sugerem Lindblad e Popkewitz (2004), como também migrar e se transformar em níveis mais próximos, por exemplo, das DCF para as DCL. Não

2 Mobilizamos o termo, tendo em vista contribuição de Courtine (1981), a partir da teorização de Foucault (2007). Conforme nos diz o autor, os enunciados encontram-se no interdiscurso, que é a instância de constituição dos sentidos, por estar ali todo o conjunto de formulações ditas e esquecidas. Por isso, diferentemente das formulações que se esgotam ao serem ditas, os enunciados se repetem. 
queremos com isso mostrar-nos contrários ou rejeitar noções que se tornam disseminadas. A questão que colocamos aqui é a de investigar a maneira pela qual essas noções aparecem como fruto de um discurso que pode ser identificado como pós-moderno e, principalmente, como elas se tornam fluidas, mutantes, tendo, assim, seus sentidos desdobrados. Sobre esse aspecto, a interpretação de Demo (1999, p. 25-26), a respeito da LDB no 9394, de 20/12/1996 também alerta educadores de um modo geral. Para ele, apesar de a noção de "flexibilidade" ser apropriada ao contexto educacional, alguns riscos (deslizamentos, diríamos) devem ser observados, pois "a flexibilidade pode ser confundida com o abuso do direito de interpretar", como também "pode ser confundida com certo "vale-tudo"'.

\section{Entre o necessário e o contingente}

Quanto ao perfil dos formandos, julgamos ser importante refletir um pouco mais sobre "as relações com o outro", mencionado no trecho das DCL que transcrevemos:

O objetivo do Curso de Letras é formar profissionais interculturalmente competentes, capazes de lidar, de forma crítica, com as linguagens, especialmente a verbal, nos contextos oral e escrito, e conscientes de sua inserção na sociedade e das relaçôes com o outro. (CNE/CES, 2001, grifos nossos).

Como encarar esse "outro" sem incorrer nos conceitos tão amplamente difundidos sobre respeito ao outro, direito do outro etc.? As considerações de Bakhtin (2003) ampliam essa concepção de que o "outro" também nos compõe. A questão que se coloca é: quais as representações que fazemos desse "outro"? Ou ainda, quais as representações que professores/professoresformadores ${ }^{3}$ fazem desse "outro"? Skliar (2003, p. 71), partindo das reflexôes advindas dos estudos culturais, argumenta que existe

\footnotetext{
${ }^{3}$ Empregamos a expressão "professor-formador" para fazer referência ao docente formador de novos professores.
} 
uma "regulação e um controle que define para onde olhar, como olhamos quem somos nós e quem são os outros e, finalmente, como o nosso olhar acaba por sentenciar como somos nós e como são os outros”. Argumenta, também, que há uma banalização do emprego do termo "o outro" em contextos educacionais (2003, p. 29). Consideramos, então, que essas reflexões, associadas à falta de compreensão das relações dialógicas imbricadas com o seu uso, poderão perpetuar visões distorcidas e tendenciosas que sufocarão as diferenças inerentes a cada indivíduo, ao espaço sala de aula e à escola de uma maneira mais ampla.

Tomemos outro excerto das DCL, ainda abordando a questão do perfil do profissional formado pelo curso de Letras:

Independentemente da modalidade escolhida, o profissional em Letras deve ter domínio do uso da língua ou das línguas que sejam objeto de seus estudos, em termos de sua estrutura, funcionamento e manifestações culturais, além de ter consciência das variedades linguísticas e culturais. Deve ser capaz de refletir teoricamente sobre a linguagem, de fazer uso de novas tecnologias e de compreender sua formação profissional como processo contínuo, autônomo e permanente. A pesquisa e a extensão, além do ensino, devem articular se neste processo. O profissional deve, ainda, ter capacidade de reflexão crítica sobre temas e questóes relativas aos conhecimentos linguísticos e literários (CNE/CES, 2001, grifos nossos).

Encontramos, nesse excerto, qualidades que são esperadas do profissional formado pelo curso de Letras. Primeiramente, destacamos o efeito da busca pela completude, expresso por meio dos vocábulos “domínio" da língua-alvo (sobre estrutura, funcionamento e manifestaçôes culturais) e "consciência" (sobre variedades linguísticas e culturais). Percebemos que esse desejo de completude, ou seja, conhecer todos os aspectos relacionados à língua-alvo e ter consciência sobre suas variedades implicam uma busca constante. O que significa para um aluno ter domínio sobre as manifestações culturais, nas quais essa língua-alvo está envolvida? Considerando a rapidez com que as informações circulam e, consequentemente, a fluidez dos conceitos e ideias por elas veiculadas, poderíamos ainda questionar em qual momento é possível afirmar que se tem o domínio da estrutura e do funcionamento dessa 
língua, por exemplo. Some-se a isso, a rapidez com que novas palavras são criadas e/ou transformadas em virtude de mudanças sociais, políticas e econômicas.

De modo similar, a palavra "consciência" também sugere totalidade de conhecimento sobre as variedades linguísticas e culturais, implicando uma busca incessante. Tal efeito é reforçado, ao se propor que o "profissional em Letras" seja capaz de compreender sua formação por meio de um processo "contínuo, autônomo e permanente". Cria-se, dessa forma, uma proposição para que a formação nunca termine, esboçando o perfil de um aprendiz que pode ser caracterizado como sendo um aprendiz para toda a vida (lifelong learner). Há, sobretudo, um compartilhamento dessa formação. Podemos dizer até que há uma transferência de dever do professor/professor-formador para o aluno, inculcada por meio da qualidade "autonomia". Pensamos que essa "compreensão do processo de formação" funciona como o estabelecimento de um compromisso entre aluno e professor/professor-formador, no qual esse se responsabiliza pela assimilação, o entendimento, de que o aluno tome para si sua formação. Esse aluno, portanto, deve saber se autogovernar, deve ter liberdade para administrar, selecionar, produzir conhecimentos para sua formação. Vemos essa "transferência de autonomia" para o futuro profissional como fruto da desregulamentação de deveres que a pós-modernidade imprime (BAUMAN, 2001). Julgamos pertinente inserir qualidades como autonomia e interesse pelo aperfeiçoamento contínuo na formação de professores, mas acreditamos que a abertura dessa perspectiva merece escrutínio a fim de termos um painel de como essa relação pode acontecer na vida do curso. A pergunta que se impõe, então, é saber como ocorre esse compartilhamento da responsabilidade pela formação. Salientamos ainda o fato de que, além de possuir domínio e consciência sobre a língua-alvo, esse profissional deve ter reflexão crítica, ser capaz de refletir teoricamente sobre a linguagem e fazer uso de novas tecnologias.

Não estamos discutindo a validade dessas noções e qualidades para a educação ou para educadores e aprendizes. Nosso propósito, reiteramos, é refletir sobre os efeitos de sentido desses conceitos 
inseridos na realidade escolar e, principalmente, sobre as possíveis decorrências que essas noções podem promover. Partindo-se da questão do perfil do formando, que foi acima discutido, pensamos que é possível ocorrer, durante o processo de formação, a construção de um duplo que classificamos como necessário/contingente. Como esse perfil deve apresentar as qualidades mencionadas (domínio, consciência etc.), é preciso indagar sobre os mecanismos a serem colocados em uso na determinação ou escolha dos conteúdos formadores que preparem o futuro profissional para conseguir essas qualidades. Como se dão no interior de um curso de formação de professores as discussões e escolhas das teorias sobre a linguagem, por exemplo? Ou ainda, como a pesquisa e a extensão serão articuladas para tornar o futuro professor autônomo? Como ocorre a inclusão de novas tecnologias que visem formar um profissional crítico? Enfim, essa sequência de questões elencadas nos faz pensar que ao tentar determinar os conteúdos que possam ser, ou possam desenvolver "domínio", "consciência", "reflexão crítica" etc., fatalmente, haverá um deslizar de objetivos que irão oscilar entre conceitos necessários ou contingentes. Podemos supor algumas perguntas, tais como: qual a necessidade de incluir determinado conteúdo se ele será apresentado futuramente por outro professor, ou de outra forma? Qual a necessidade de discutir certos conceitos, se o aluno não pretende seguir determinado rumo em seus estudos, ou se essas discussões poderão ocorrer ainda em momento posterior, em virtude da complexidade de uma abordagem teórica, por exemplo? Poderíamos ainda continuar com outras teorizações, porém o que desejamos enfatizar é a constituição dessa oscilação disjuntiva ao se pensar sobre as escolhas curriculares. Em ambas as possibilidades, essa oscilação entre o par necessário/contingente irá se configurar. Por um lado, se a busca pela completude for assumida como possível, a escolha entre conhecimentos necessários para atingi-la determinará aqueles que são contingentes. Por outro lado, se a totalidade não for considerada como meta factível, muitos desses conhecimentos serão contingentes, fazendo com que as escolhas incidam sobre alguns "necessários" apenas. 
Identifiquemos, nos trechos que se seguem, as determinações acerca das competências e habilidades dos formandos:

[...] o curso de Letras deve contribuir para o desenvolvimento das seguintes competências a habilidades:

- domínio do uso da língua portuguesa ou de uma língua estrangeira, nas suas manifestações oral e escrita, em termos de recepção e produção de textos;

- eflexão analítica e crítica sobre a linguagem como fenômeno psicológico, educacional, social, histórico, cultural, político e ideológico;

- visão crítica das perspectivas teóricas adotadas nas investigaçóes linguísticas e literárias, que fundamentam sua formação profissional;

- preparação profissional atualizada, de acordo com a dinámica do mercado de trabalho;

- percepção de diferentes contextos interculturais;

- utilização dos recursos da informática;

- domínio dos conteúdos básicos que são objeto dos processos de ensino e aprendizagem no ensino fundamental e médio;

- domínio dos métodos e técnicas pedagógicas que permitam a transposição dos conhecimentos para os diferentes níveis de ensino. (CNE/CES, 2001, grifos nossos).

Chamamos a atenção para a opacidade das características desejadas: "interculturalmente competentes", "conscientes de sua inserção na sociedade e das relações com o outro", apontados no primeiro excerto da seção, e "percepção de diferentes contextos interculturais", no excerto acima. Reconhecemos que competência, consciência e percepção são noções complexas que merecem apuro de detalhes, no entanto, não vemos nas DCL discussão no sentido de mostrar algumas dimensôes desses conceitos. Não é nosso objetivo, tampouco, analisá-los neste trabalho, entretanto, salientamos o fato de a densidade de tais conceitos fazer com que a formulação "preparação profissional atualizada, de acordo com a dinâmica do mercado de trabalho" torne-se mais evidente, realçada, pois, ao contrário dos conceitos anteriores, nesse, a "preparação" é orientada, detalhada. Notemos como esse efeito é 
produzido pelo marcador discursivo "de acordo com", iniciando a incisa que se segue.

Destacamos, ainda, que as formulações acima "preparação profissional atualizada, de acordo com a dinâmica do mercado de trabalho" e "utilização dos recursos da informática" são noções que remetem a conceitos elaborados também em nível mundial, conforme sugerem Lindblad e Popkewitz (2004). Entretanto, conforme argumentamos em outro trabalho (COSTA, 2008), tais conceitos passam por uma alquimia local que os fazem adquirir novas "roupagens". Logo, cabe-nos observar os deslizamentos, as "roupagens", as transformações desses referidos conceitos inseridos no âmbito que aqui investigamos. Além dos oito quesitos listados no excerto anterior, há, ainda, em outro momento do texto, formulação sugerindo que o formando "deverá ter, também, a capacidade de resolver problemas, tomar decisóes, trabalbar em equipe e comunicar-se dentro da multidisciplinaridade dos diversos saberes que compõem a formação universitária em Letras" (CNE/CES, 2001, p. 30, grifos nossos). A ênfase para "resolver problemas", "tomar decisões" e "trabalhar em equipe" nos faz lembrar, novamente, da análise de Giroux (1997) sobre a proletarização do trabalho docente. Podemos ver esses conceitos aplicados a uma perspectiva educacional, no entanto, nosso conhecimento de mundo nos informa que essas são palavras-chave, conceitos amplamente difundidos no mercado de trabalho contemporâneo. Conforme Orlandi (2001, p. 53), "O discurso é uma dispersão de textos”. Isso nos faz perceber que os sintagmas: "resolver problemas", "tomar decisões" e "trabalhar em equipe" são materializações linguísticas que nos remetem a um discurso empresarial. É válido, sobretudo, observar que essas formas vêm expressas com emprego de verbos - que transmitem dinamismo e diligência - diferentemente das formulações anteriores expressas com substantivos, que, conforme já mencionamos, ajudam a criar uma certa vaguidade no discurso. Assim sendo, nesse ponto da reflexão, podemos concluir que as adaptações ou as transformações de sentido das palavras de ordem, no contexto analisado, apontam para um nicho predominantemente mercadológico. Cabe lembrar, aqui, análise de Moreira e Silva (1994) sobre as novas tecnologias 
e a informática. A preocupação dos autores, quando o ensaio foi produzido, residia no fato de que a ausência de uma "teorização curricular crítica" sobre tais temas poderia deixar a educação e o currículo à mercê de objetivos mercadológicos.

Essas exigências do perfil do profissional de Letras nos mostram um painel dividido entre noções, expectativas, conceitos complexos e de vastas dimensões de um lado, e de outro, noções mais próximas do aprendiz, mais pragmáticas, mais direcionadas. Notemos como "fazer uso de novas tecnologias" e "utilização dos recursos da informática” são noções mais específicas, mais procedimentais. Vemos, dessa forma, a construção de uma postura disjuntiva: de um lado, temos requisitos mais precisos e, de outro, noções mais gerais. Podemos ainda enfatizar que a expressão "fazer uso de novas tecnologias" causa um efeito paradoxal, pois "fazer uso de" parece iniciar a descrição de um procedimento mais específico, no entanto, a inclusão de "novas tecnologias", conforme já apontamos, é também um conceito amplo, ocorrência que faz a expressão ter efeito de oxímoro. Na nossa interpretação, isso parece figurar um deslizamento de sentidos, ou uma bifurcação, conforme já vimos empregando. Voltemos nossa atenção para outros aspectos apresentados nas DCL.

\section{Entre a teoria e a prática}

Com relação aos conteúdos curriculares, tomemos o excerto seguinte:

Considerando os diversos profissionais que o curso de Letras pode formar, os conteúdos caracterizadores básicos devem estar ligados à área dos Estudos Lingüísticos e Literários, contemplando o desenvolvimento de competências a habilidades específicas. Os estudos lingüísticos e literários devem fundar se na percepção da língua e da literatura como prática social e como forma mais elaborada das manifestaçôes culturais. Devem articular a reflexão teórico crítica com os dominios da prática - essenciais aos profissionais de Letras, de modo a dar prioridade à abordagem intercultural, que concebe a diferença como valor antropológico e como forma de desenvolver o espirito critico frente à realidade. (CNE/CES, 2001, grifos nossos). 
Inicialmente, chamamos a atenção para a formulação: "abordagem intercultural que concebe a diferença como valor antropológico e como forma de desenvolver o espírito crítico frente à realidade". É mister salientar que não identificamos, nas DCL e nas DCF, uma ênfase para a construção de currículos contextualizados. Ou seja, não há referências à importância do conhecimento local, situacional. Acreditamos que caberia mencionar no texto - de maneira explícita -, que os projetos curriculares deveriam incluir o conhecimento trazido por diversas representações encontradas na sociedade (grupos de diferentes raças, crenças, origens etc.), na tentativa de desencorajar qualquer forma de preconceito. No entanto, vemos que, no discurso, a formulação "priorização da abordagem intercultural" parece prescindir de comentários. Dizer-se inclusivo e consciente das diferenças não é suficiente para possibilitar uma conduta pedagógica que realmente dê conta de verdades locais e contextualizadas.

Sobre essa questão, evocamos Orlandi (1997, p. 12) e sua reflexão sobre o silenciamento. Segundo essa autora, "há um sentido no silêncio", isto é, essa ausência também significa algo. Acreditamos que apenas o emprego dos termos "diversidade", "heterogeneidade", mencionados no texto e analisados anteriormente, não reproduzem a complexidade inerente a esses conceitos.

Nessa mesma linha de reflexão, outro aspecto que é "posto em silêncio" é a questão do material didático, considerando aqui não somente livros que, porventura, possam ser adotados em algumas instituições de ensino superior, mas também para indicar a seleção de textos ou outros recursos que possam servir de fonte para discussóes que propiciem a aprendizagem. Vale ressaltar que não esperamos uma lista de opções ou guias, entretanto, a ausência de um apelo para que se considerem no currículo formas locais de conhecimento, conforme apontamos, poderá deixar os elaboradores do currículo "oficial" à mercê das práticas dominantes, desconsiderando, consequentemente, que professores e alunos são produtores de conhecimento. Coracini (1999) alertou para o fato de o livro didático poder colaborar para a manutenção de uma determinada 
ideologia dominante. Sabemos que os livros didáticos buscam sempre uma linearidade no aprendizado, uma homogeneização nos procedimentos, sem mencionar a questão mercadológica envolvida; dessa forma, é compreensível que tal aspecto não esteja contemplado nesses documentos. Contudo, a ausência de orientação para que coordenadores, professores, orientadores pedagógicos estejam alertas sobre o caráter problemático do material didático e das implicações da sua escolha pode fazer com que antigas representações do livro didático e antigos hábitos continuem a vigorar.

Ainda com relação aos conteúdos curriculares, vemos na formulação: "reflexão teórico crítica com os domínios da prática" outro exemplo de construção de pares, aspecto que temos buscado identificar no discurso desses documentos. Estamos apontando para os efeitos produzidos nas construçôes "reflexão (teóricocrítica)" com "domínios (da prática)", ou seja, entendemos que o par teoria/prática está posto nessas orientações, com ênfase, sobretudo, para a prática. Note-se o efeito da incisa "essenciais aos profissionais de Letras", que produz um efeito fundante ou estruturante na formação de professores. Considerando a forma e o objetivo das DCL, entendemos que a maneira pela qual essa questão foi introduzida propicia a instauração da noção de que essa dicotomia é parte inerente do professor.

A questão que merece ser posta, na nossa visão, é pensar não em construções binárias, mas sim como pares que são partes de um mesmo processo (POPKEWITZ, 1998). Vale ressaltar a sugestão de que "os domínios da prática" devem priorizar a "abordagem intercultural", conforme transcrito acima. Atentemos para o caráter disjuntivo nessa formulação, pois entendemos que a questão da abordagem intercultural (ênfase em sua priorização) em si já envolve um conceito teórico. Ou seja, há uma sugestão para se valorizar a prática (constituição do par teoria/prática), mas, ao mesmo tempo, essa prática remete a uma teoria que lhe é inerente. Ao instaurar uma disjunção, um desses polos (prática) volta a ligar-se com o outro como resultado dessa separação. Além dessa formulação, há também, na sequência, outra proposta: “o processo articulatório entre habilidades e competências no curso de 
Letras pressupõe o desenvolvimento de atividades de caráter prático durante o período de integralização do curso" (CNE/CES, 2001, p. 31, grifos nossos). Reiteramos comentário elaborado sobre a formulação anterior, pois, nesse, a divisão entre teoria e prática é também sugerida. A articulação entre habilidades e competências implica, igualmente, um conceito teórico. Lembramos que argumentamos, em trabalho anterior (COSTA, 2008), como vimos que alguns modos de dizer podem dar início ou reforçar a dicotomia teoria/prática na educação. Com isso, perde-se de vista o espaço entre esses dois polos, que acreditamos ser o campo da produção, da (re)formulação dos sentidos. Como os conceitos se bifurcam naturalmente, se a ambivalência subjaz, caberia pensar sobre a articulação desses polos como formas complementares, como expressões do mesmo. Desse modo, a reflexão poderia centrar-se em formas de aproximação desses "opostos" ao invés de intensificar dicotomias. No entanto, percebemos no discurso desses documentos efeitos que reforçam a disjunção.

Sobre a estruturação do curso, há uma solicitação para que se observe o que as DCF preconizam, em seu Art. $5^{\circ}$, que transcrevemos abaixo:

Art. $5^{\circ} \mathrm{O}$ projeto pedagógico de cada curso, considerado o artigo anterior, levará em conta que:

I a formação deverá garantir a constituição das competências objetivadas na educação básica;

II o desenvolvimento das competências exige que a formação contemple diferentes âmbitos do conhecimento profissional do professor;

III a seleção dos conteúdos das áreas de ensino da educação básica deve orientar-se por ir além daquilo que os professores irão ensinar nas diferentes etapas da escolaridade;

IV os conteúdos a serem ensinados na escolaridade básica devem ser tratados de modo articulado com suas didáticas específicas;

$\mathrm{V}$ a avaliação deve ter como finalidade a orientação do trabalho dos formadores, a autonomia dos futuros professores em relação ao seu processo de aprendizagem e a qualificação dos profissionais com condições de iniciar a carreira. (CNE/CP, 2002, grifos nossos). 
A apresentação dessa orientação, disposta em forma de artigos, parágrafos únicos, itens e subitens, imprime ao documento um efeito legislador, que deixa os indivíduos submissos a ela. Vemos essa marca como reflexo de um discurso jurídico, portanto. Notemos como as formas deônticas nas formulaçôes (verbo "dever" em algumas de suas variantes: deverá, deve, devem), em conjugação perifrástica com verbos no infinitivo (garantir, orientar-se, ser, ter) torna o discurso marcadamente intimidador. Lembramos, aqui, reflexões de Foucault (2003b) sobre o poder disciplinar que postula que a vigilância hierárquica, a sanção normalizadora e o exame são meios de controle, parte de um processo de adestramento dos corpos e do espírito. Acreditamos que as formulações presentes nesse artigo das DCF (e em vários outros), com o verbo "dever", funcionam na direção de auxiliar a padronizar uma prática homogênea não apenas em relação à estrutura dos cursos, mas também no que diz respeito aos conteúdos, métodos, procedimentos, materiais didáticos etc. Na verdade, a perspectiva foucaultiana de poder contribui para visualizarmos nesses documentos, de uma maneira geral, formas de conduta que o Estado pretende criar; como por exemplo, o caráter marcadamente empresarial na escola, ou ainda, enunciados que - por não apresentar clareza - acabam por incentivar e legitimar práticas homogeneizadoras. Nossa reflexão sobre esse aspecto retoma, dessa maneira, comentário anterior a respeito da determinação/seleção de características que sejam necessárias, importantes, essenciais para a estrutura do curso em oposição àquelas que são contingentes. De modo semelhante, o mesmo processo poderá ocorrer quanto a essa questão da estruturação do curso. Ao se elaborar o projeto pedagógico, na tentativa de buscar elementos (partes) para compor esse projeto (conteúdos, disciplinas, módulos, temas etc.), poderá haver um contínuo deslizar entre os elementos considerados importantes para poder "cumprir" as orientações postuladas e aqueles que não são contingentes, portanto.

A complexidade dos temas com os quais temos nos deparado nas Diretrizes Curriculares, tais como "novas tecnologias", 
"termos éticos", "flexibilidade", "diversidade", entre outros, nos faz lembrar trabalho de Souza (2003) sobre políticas curriculares. Segundo a autora, diante da complexidade de determinados conceitos apresentados nos Parâmetros Curriculares, "'o professor experimenta uma espécie de sensação de culpa que o remete ao lugar da incompetência” (p. 344) por não compreender algumas orientações nem torná-las factíveis. Outra questão levantada pela autora é sobre a transversalidade. Para ela, alguns temas (meio ambiente, ética, pluralidade cultural etc.) acabam se transformando em disciplinas escolares por serem considerados "produto da análise do governo" (p. 340). Desse modo, a análise da pesquisadora nos apoia na ênfase para um exame minucioso acerca dos conceitos apresentados nas Diretrizes Curriculares para que temas pluridisciplinares não acabem se tornando disciplinas em si.

\section{Avaliar ou estigmatizar?}

Passemos para a última seção das DCL, que trata da questão da avaliação. Observemos as seguintes formulações que tratam desse item, primeiramente nas DCL para, em seguida, compará-las com as sugestôes propostas nas DCF:

A avaliação a ser implementada pelo colegiado do curso de Letras deve constituir processo de aperfeiçoamento continuo e de crescimento qualitativo, devendo pautar se:

- pela coerência das atividades quanto à concepção e aos objetivos do projeto pedagógico e quanto ao perfil do profissional formado pelo curso de Letras;

- pela validação das atividades acadêmicas por colegiados competentes;

- pela orientação acadêmica individualizada;

- $\quad$ pela adoção de instrumentos variados de avaliação interna;

- pela disposição permanente de participar de avaliação externa. (CNE/ CES, 2001, grifos nossos). 
Art. $8^{\circ}$ As competências profissionais a serem constituídas pelos professores em formação, de acordo com as presentes Diretrizes, devem ser a referência para todas as formas de avaliação dos cursos, sendo estas:

I periódicas e sistemáticas, com procedimentos e processos diversificados, incluindo conteúdos trabalhados, modelo de organização, desempenho do quadro de formadores e qualidade da vinculação com escolas de educação infantil, ensino fundamental e ensino médio, conforme o caso;

II feitas por procedimentos internos e externos, que permitam a identificação das diferentes dimensões daquilo que for avaliado;

III incidentes sobre processos e resultados. (CNE/CP, 2002, grifos nossos).

Para abordarmos esse item da avaliação, vale lembrar, novamente, a interpretação de Foucault (2003b, p. 156) sobre um dos mecanismos de poder disciplinar: o exame. Sua reflexão acerca desse tema preconiza que "o exame supóe um mecanismo que liga um certo tipo de formação de saber a uma certa forma de exercício de poder". Sintetizando o que nos diz esse pensador, o exame é uma estratégia do poder que, de maneira tácita, transforma seus "súditos" em objetos. Isso pertence a uma parte daquilo que esse filósofo designou como um dos três modos de objetivação do sujeito explicitados em seu texto "The subject and power" (1983, p. 208), no qual ele sintetiza e discute os objetivos de suas pesquisas. Voltando à sua reflexão sobre o exame, outro postulado revela que, além da transformação em objeto, os alunos (empregamos esse termo, pois é o que nos interessa neste trabalho) passam a ser considerados por meio de documentos e registros. Isso nos leva a sua última postulação sobre o exame que diz respeito ao indivíduo visto como um "caso". Ou seja, olhar os alunos como casos que podem ser estudados, medidos, classificados, acaba por facilitar que o poder continue a interferir e a definir o que deve ser mantido, excluído, alterado etc.

Ampliando essa reflexão, vale, então, observar a formulação "disposição permanente de participar de avaliação externa", presente nas DCL, como também a formulação das DCF, na qual há uma sugestão para que a avaliação dos cursos seja feita 
por "procedimentos internos e externos". Voltando à reflexão de Foucault sobre os modos de objetivação, podemos acrescentar que tal formulação revela que a estruturação dos cursos deve estar submetida a práticas de divisão e consequente classificação. Cabe interrogar se tais práticas não ajudariam a criar um conteúdo curricular visando somente à preparação, ao treinamento para a obtenção de "sucesso" nessas avaliações. Ou seja, corre-se o risco de essas práticas avaliativas atuarem simplesmente como formas que estigmatizam e rotulam. Lembramos que instrumentos como ENADE (Exame Nacional de Desempenho de Estudantes), ENEM (Exame Nacional do Ensino Médio), entre outros, acabam sendo maneiras de catalogar, classificar resultados e, por meio deles, alunos e professores. Os rankings acerca das instituições submetidas a tais exames, constantemente, divulgados e explorados pela mídia exemplificam nossa asserção. Com isso, não pretendemos assumir posição contrária a tais mecanismos de avaliação, pois entendemos que podem gerar competitividade, levando aquelas instituições relacionadas na base desses rankings a buscar aperfeiçoamentos na área pedagógica, curricular etc. A questão que colocamos aqui é a de investigar se os processos de avaliação, baseados nas propostas das Diretrizes Curriculares, serão amplamente discutidos e (re)definidos. Entendemos que não é tarefa fácil detalhar o que seria uma avaliação vista como "processo de aperfeiçoamento contínuo". Nossa crítica não é com relação à ausência dessa elaboração no texto, tampouco que a questão da avaliação deva ser (re)definida a partir dos documentos mencionados. Nossa argumentação é no sentido de salientar que a ausência de detalhamento pode reforçar a complexidade do tema. Outrossim, por supormos que no interior das instituições de ensino as discussões sobre a questão da avaliação não são rotineiras, nossa hipótese é que as práticas avaliativas continuarão a contribuir para perpetuar rituais disciplinadores que, ao invés de propiciar crescimento intelectual e crítico, acabam por validar prejulgamentos sobre grupos, níveis de aprendizagem e local de formação dos professores (instituições de ensino superior). 
Sublinhamos que os adjetivos "periódicas" e "sistemáticas", presentes nas DCF para descrever as formas de avaliação, remetem às locuçóes adjetivas: "processo de aperfeiçoamento contínuo e de crescimento qualitativo" ou ainda, "instrumentos variados de avaliação", presentes nas DCL. Observamos a proximidade desses termos que poderíamos justificar por meio da relação interdiscursiva ${ }^{4}$ dessas formaçôes. Vemos, ainda, que os termos pertencem a uma mesma família parafrástica, segundo Pêcheux e Fuchs (1997, p. 169). Para os autores, "a produção do sentido é estritamente indissociável da relação de paráfrase”, desse modo, permitimo-nos afirmar que os termos analisados apresentam aproximações semânticas, mantendo entre si uma "matriz de sentido". Para o que nos interessa nessa análise, cabe observar que, em ambos os documentos, os adjetivos contribuem para criar esse efeito de opacidade no discurso. Advogamos, dessa forma, que a diluição da concepção das práticas avaliativas pode continuar a transformá-las em mecanismos que apenas pontuem, classifiquem e dividam os alunos. Ou seja, divisamos, novamente, outro momento no qual conceitos se bifurcam, criando pares que acabam por revelar a mesma origem constitutiva, que aqui denominamos avaliar/estigmatizar. No caso, os objetivos da avaliação preconizados para promover "aperfeiçoamento" e "crescimento" poderão também ser desviados do seu propósito, figurando como indicadores que ajudarão a manter ou a criar designações para alunos e instituições.

\section{Considerações finais}

Pelas reflexões expostas neste artigo, acreditamos que, de um modo geral, essa análise possibilitou-nos ponderar sobre algumas questões a respeito dos cursos de formação de professores. Ao longo

4 Conforme esclarecido anteriormente, o interdiscurso é a instância de constituição dos sentidos, por estar ali todo o conjunto de formulações ditas e esquecidas (COURTINE, 1981). 
desse artigo, dedicamo-nos a investigar os modos de irrupção da ambivalência presentes nas Diretrizes Curriculares Nacionais por meio de algumas construçôes disjuntivas.

Sabemos que tais documentos não se propõem a definir procedimentos específicos para a formação de professores e formandos de Letras, nem é isso que buscamos. Não pretendemos defender as orientações ali preconizadas, tampouco rejeitá-las. Conforme dissemos, nosso objetivo foi tomar tais documentos como exemplares de discurso. Assim, fazemos algumas reiterações.

Primeiramente, vimos como as propostas/orientações de mudanças educacionais estão vinculadas, particularmente, às transformações no mercado de trabalho e profissional. Apontamos como algumas palavras e expressões se constituem prioridade na formação, quais sejam: "flexibilidade", "diversidade", "práticas investigativas", "tecnologias da informação", "materiais de apoio inovadores" e "colaboração e trabalho em equipe". Conforme enfatizamos, acreditamos que esses conceitos devem ser cuidadosamente observados na realidade escolar, incluindo aqui, reformas curriculares, projetos pedagógicos e cursos de formação de professores, com o objetivo de entender como os sujeitos envolvidos nesse processo atribuem sentidos a essas concepções. Assim sendo, considerando alguns efeitos produzidos pelo discurso na forma de construções disjuntivas com relação a temas como o perfil do aluno, a avaliação, o conteúdo curricular, somados, ora à complexidade dos conceitos discutidos (flexibilidade, diferença, o outro etc.), ora ao "silenciamento" sobre alguns tópicos (termos éticos, livro didático, valorização do contexto), sinalizamos que, de acordo com nossa ótica, essas palavras podem assumir finalidade puramente mercadológica. Apesar de a noção de flexibilidade figurar como princípio fundante nos documentos, apropriado para uma condição pós-moderna, deparamo-nos com orientações que nos remetem a fundamentos da modernidade, tais como: domínio, controle, totalidade etc. De uma perspectiva discursiva, tal dissonância de vozes não nos causa estranhamento. Há de se ressaltar que essas vozes são representativas de um conflito de paradigmas 
da pós-modernidade, sobretudo, no campo educacional. Contudo, o surgimento de conceitos que demandam escrutínio e constante reflexão, ao lado de orientações pontuais com efeitos de sentido afinados com interesses mercadológicos, além de poder render uma noção de performatização à formação do professor, pode também estimular ideais modernistas, por parecerem mais "seguros", levando assim a uma perpetuação de determinadas representaçôes sobre a formação de professores, sobre o professor-formador e, principalmente, sobre algumas práticas docentes na Educação Básica.

\section{Referências}

APPLE, Michael W. A política do conhecimento oficial: faz sentido a idéia de um currículo nacional? In: MOREIRA, Antônio Flávio Barbosa; SILVA, Tomaz Tadeu da. (Org.). Currículo, cultura e sociedade. São Paulo: Cortez, p. 59-91, 1994.

AUTHIER-REVUZ, Jacqueline. Entre a transparência e a opacidade: um estudo enunciativo do sentido. Porto Alegre: EDIPUCRS, 2004.

AUTHIER-REVUZ, Jacqueline. Palavras incertas: as não-coincidências do dizer. Campinas: Ed. da UNICAMP, 2001.

BAKHTIN, Mikhail. Estética da criação verbal. 4 ed. São Paulo: Martins Fontes, 2003.

BARRETO, Raquel Goulart. A presença das tecnologias. In: FERRAÇO, Carlos Eduardo. (Org.). Cotidiano escolar, formação de professores (as) e currículo. São Paulo: Cortez, p. 141-157, 2005.

BAUMAN, Zygmunt. Modernidade líquida. Rio de Janeiro: Jorge Zahar, 2001.

CONSELHO NACIONAL DE EDUCAÇÃO / CÂMARA DE EDUCAÇÃO SUPERIOR. Parecer CNE/CES 492/2001. Diretrizes Curriculares Nacionais dos cursos de Filosofia, História, Geografia, Serviço Social, Comunicação Social, Ciências Sociais, Letras, Biblioteconomia, Arquivologia e Museologia. Diário Oficial da União, Brasília, DF, Seção le, p. 50, 9 de jul. 2001. 
CONSELHO NACIONAL DE EDUCAÇÃO / CONSELHO PLENO. Resolução CNE/CP 1, de 18 de fevereiro de 2002. Institui Diretrizes Curriculares Nacionais para a Formação de Professores da Educação Básica, em nível superior, curso de licenciatura, de graduação plena. Diário Oficial da União, Poder Executivo, Brasília, DF. Seção 1, p. 31, 9 de abr. 2002.

CORACINI, Maria José. Pós-modernidade e novas tecnologias - no discurso do professor de línguas. In: CORACINI, Maria José. A celebração do outro: arquivo, memória e identidade: línguas (materna e estrangeira), plurilinguismo e tradução. Campinas: Mercado de Letras, p. 209-224, 2007.

CORACINI, Maria José. O processo de legitimação do livro didático na escola de ensino fundamental e médio: uma questão de ética. In: CORACINI, Maria José. (Org.). Interpretação, autoria e legitimação do livro didático: língua materna e língua estrangeira. Campinas: Pontes, p. 33-43, 1999.

COSTA, Marco Antônio Margarido. Do sentido da contingência à contingência da formação: um estudo discursivo sobre a formação de professores de inglês. 2008. 23lfs. Tese (Doutorado em Estudos Linguísticos e Literários em Inglês) - Faculdade de Filosofia, Letras e Ciências Humanas, Universidade de São Paulo, São Paulo, 2008.

COURTINE, Jean-Jacques. Quelques problèmes théoriques et méthodologiques en analyse du discours, à propos du discours communiste adressé aux chrétiens. Langages, Paris, n 62, p. 9-128, 1981.

DEMO, Pedro. A nowa LDB: ranços e avanços. 8 ed. Campinas: Papirus, 1999. FOUCAULT, Michel. A arqueologia do saber. 7 ed. Rio de Janeiro: Forense Universitária, 2007.

Verdade e poder. In: MACHADO, Roberto. (Org.). Micro-

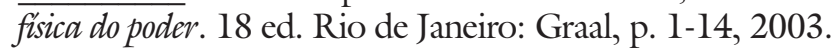

Vozes, 2003b.

Vigiar e punir: nascimento da prisão. 27 ed. Petrópolis:

Governamentalidade. In: MACHADO, Roberto. (Org.). Microfisica do poder. 18 ed. Rio de Janeiro: Graal, p. 277-293, 2003c. 
Soberania e disciplina. In: MACHADO, Roberto. (Org.). Microfísica do poder. 18 ed. Rio de Janeiro: Graal, p. 179-191, 2003c.

The subject and power. In: DREYFUS, Hubert L.; RABINOW, Paul. Michel Foucault: beyond structuralism and hermeneutics. 2nd ed. Chicago: The University of Chicago Press, p. 208-226, 1983.

GIROUX, Henry Armand. Os professores como intelectuais: rumo a uma pedagogia crítica da aprendizagem. Porto Alegre: Artes Médicas, 1997.

HOUAISS, Antonio; MELLO FRANCO, Francisco Manoel de; VILLAR, Mauro de Salles. (Ed.). Dicionário eletrônico Honaiss da língua portuguesa. Versão 1.0. [Rio de Janeiro]: Objetiva, 2001. [CD-ROM.]

KINCHELOE, Joe L. A formação do professor como compromisso politico: mapeando o pós-moderno. Porto Alegre: Artes Médicas, 1997.

KIZILTAN, Mustafá Ü.; BAIN, William J.; CAÑIZARES M., Anita. Condições pós-modernas: repensando a educação pública. In: SILVA, Tomaz Tadeu da. (Org.). Teoria educacional critica em tempos pós-modernos. Porto Alegre: Artes Médicas, p. 205-232, 1993.

LINDBLAD, Sverker; POPKEWITZ, Thomas Stanley. (Ed.). Educational restructuring: international perspectives on traveling policies. Greenwich, Connecticut: Information Age Publishing, 2004.

LYOTARD, Jean-François. Opós-moderno. Rio de Janeiro: JoséOlympio, 1986.

MAGUIRE, Meg. The modern teacher: a textual analysis of educational restructuration. In: LINDBLAD, Sverker; POPKEWITZ, Thomas Stanley (Ed.). Educational restructuring: international perspectives on traveling policies. Greenwich, Connecticut: Information Age Publishing,p. 121-141, 2004.

MCLAREN, Peter. Teoria crítica e o significado da esperança. In: GIROUX, Henry Armand. Os professores como intelectuais: rumo a uma pedagogia crítica da aprendizagem. Porto Alegre: Artes Médicas,p. xi-xxi., 1997.

MOREIRA, Antônio Flávio Barbosa; SILVA, Tomaz Tadeu da. Sociologia e teoria crítica do currículo: uma introdução. In:

(Org.). Currículo, cultura e sociedade. São Paulo: Cortez, p. 7-37, 1994.

ORLANDI, Eni Puccinelli. Discurso e leitura. 6 ed. São Paulo: Cortez; Campinas: Ed. da UNICAMP, 2001. 
. As formas do silêncio: no movimento dos sentidos. 4 ed. Campinas: Ed. da UNICAMP, 1997.

PÊCHEUX, Michel; FUCHS, Catherine. A propósito da análise automática do discurso: atualização e perspectivas. In: GADET, Françoise; HAK, Tony. Por uma análise automática do discurso: uma introdução à obra de Michel Pêcheux. 3 ed. Campinas: Ed. da UNICAMP, p. 163-235, 1997.

POPKEWITZ, Thomas Stanley. Struggling for the soul: the politics of schooling and the construction of the teacher. New York: Teachers College, 1998.

PETERS, Michael. Governamentalidade neoliberal e educação. In: SILVA, Tomaz Tadeu da. (Org.). O sujeito da educação: estudos foucaultianos. Petrópolis: Vozes, p. 211-224, 1994.

SILVA, Tomaz Tadeu da. (Org.). Identidade e diferença: a perspectiva dos estudos culturais. 2 ed. Petrópolis: Vozes, 2003.

SKLIAR, Carlos. Pedagogia (improvável) da diferença: e se o outro não estivesse aí? Rio de Janeiro: DP\&A, 2003.

SOUZA, Deusa Maria de. Identidade transversal e política de verdades: políticas curriculares e a construção da identidade do professor de línguas estrangeiras. In: CORACINI, Maria José. (Org.). Identidade e discurso: (des)construindo subjetividades. Campinas: Ed. da UNICAMP; Chapecó: Argos Ed. Universitária, p. 337-350, 2003.

USHER, Robin; EDWARDS, Richards. Postmodernism and education. London: Routledge, 1994. 